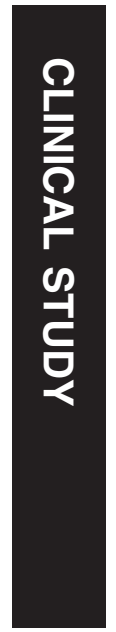

\section{The assessment and management of strabismus and amblyopia: a national audit}

\section{Abstract}

Aims To determine what systems are in
L Wickham ${ }^{1}$, C Stewart ${ }^{2}$, A Charnock ${ }^{1}$ and A Fielder ${ }^{2}$
${ }^{1}$ Western Eye Hospital London, UK

${ }^{2}$ Imperial College of Science, Technology and Medicine

London, UK

Correspondence: Prof AR Fielder Department of Ophthalmology Western Eye Hospital Imperial College School of Medicine

Marylebone Road

London NW1 5YE, UK

Tel: 02078863202

Fax: 02078863203

E-mail: a.fielder@ic.ac.uk place within ophthalmic services for the assessment and management of children suspected of having amblyopia and strabismus. To find out what methods are used for the assessment of these children. Methods A questionnaire-based study auditing 288 orthoptic departments in the UK.

Results Responses were received from $75 \%$ orthoptic departments. Most hospitals employ more than one system for the assessment of strabismus and amblyopia, which is generally dependent on route of referral. These include 'orthoptic assessment without refraction' (66\%), 'combined orthoptist and ophthalmologist assessment' $(66 \%)$, while $22 \%$ have an entirely orthoptist/optometric system.

Ophthalmologists are involved in the initial assessment in 145 units (67\%), whereas some units involve an ophthalmologist only if response to treatment is poor $(\mathbf{1 5 \%})$, or if surgery is required $(6 \%)$.

Fourteen per cent of units reviewed all children, with discharge criteria being based on normal visual acuity (52\%), accurate visual acuity (39\%) and a normal orthoptic assessment (42\%). Seventy-six per cent of units review some children, commonly as a result of family history $(55 \%)$, parental concern $(43 \%)$, poor co-operation $(30 \%)$ and young age $(72 \%)$. In the absence of squint or amblyopia children are discharged at the first visit, in only $8 \%$ of units.

There is considerable variation in the tests used to assess visual acuity. LogMAR-based tests (eg EDTRS) are not routinely used in $75 \%$ of units.

Conclusion Different systems exist for the assessment and management of squint and amblyopia across the country. While much of this variation is to be expected given their possible aetiologies, some could be reduced to produce a more cohesive service. There is also considerable scope for rationalising the tests used to screen infants and children for amblyopia and strabismus.

Eye (2002) 16, 522-529. doi:10.1038/

sj.eye. 6700136

Keywords: strabismus; amblyopia; management; assessment; audit; children; screening

\section{Introduction}

Strabismus and amblyopia are the commonest ophthalmic problems affecting young children with prevalences of $\simeq 5 \%$ of 5 year olds for strabismus, ${ }^{1-6}$ and $1.2-4.4 \%$ for amblyopia. ${ }^{1,7}$ It is a strongly held tenet, based on the concept of the sensitive period for amblyopia which ends at around 7 years, that the early treatment of amblyopia is critical and is less likely to be effective if delayed until after school entry. ${ }^{8-11}$ However, while the presence of a cosmetically obvious strabismus generates referral at any age, in amblyopia not associated with an obvious deviation the diagnosis can be delayed. ${ }^{12,13}$

UK-wide preschool vision screening was advocated in $1976^{14}$ and national preschool vision screening for amblyopia and strabismus identification was set up for children at around 3.5 years of age in 1978. By 1988, 99\% of National Health authorities had a screening programme in place. ${ }^{15}$ However, in some areas screening has never been established or has recently been disbanded-perhaps in response to the Systematic Review of $1997 .{ }^{16}$ Controversy still exists over the need for 
screening, ${ }^{15-17}$ the age at which it should be carried out $^{15,18,19}$ and the use of orthoptists ${ }^{19-22}$ within this programme. However, the Child Health Screening Subgroup of the UK National Screening Committee recommends vision screening by an orthoptist of all UK children at age $4.5-5$ years of age. ${ }^{19}$ This group also recommends that all children with major disabilities require a full ophthalmic assessment. Currently therefore in the UK amblyopia and strabismus are identified by: population screening by health visitors or orthoptists, referrals via child health surveillance programmes, or referrals by GPs and clinical medical officers (consisting of cover tests with or without visual acuity). Orthoptists may undertake primary screening or assess children in secondary referral community clinics. Some areas have no screening for strabismus and amblyopia.

Children identified by primary population screening are then referred either to an orthoptic or ophthalmic clinic. Apart from population screening, children suspected of having amblyopia or strabismus may be referred to the hospital eye service at any age, by general practitioners, community or hospital paediatricians, health visitors, school nurses or optometrists. Thus there are a number of referral routes by which children with suspected amblyopia or strabismus reach the ophthalmic service, and once there, we have anecdotal evidence that the methods of assessment and systems for management differ.

We have undertaken a survey to determine what systems are in place within ophthalmic services for the assessment and management of children suspected of having amblyopia and strabismus. We also enquired about methods of assessment of these children.

\section{Methods}

A questionnaire was sent to every UK orthoptic department on a list compiled by the British Orthoptic Society (BOS) in 1994. The questionnaire was divided into five sections:

Part 1 Requested information about systems currently in place for the assessment of strabismus and amblyopia, and the reasons for choosing them.

Part 2 Enquired about the tests used routinely in the initial assessment of children, eg methods of measuring visual acuity.

Part 3 Enquired about the management of children who had no evidence of strabismus or amblyopia at the first visit.
Part 4 Enquired about whether an entirely orthoptist/optometric service had been considered for the management of children suspected of having strabismus or amblyopia. Reasons for not wanting such a system were then asked for.

Part 5 Enquired about the involvement of an ophthalmologist in the management of children with amblyopia or strabismus.

\section{Results}

The British Orthoptic Society list contained 330 orthoptic departments. Since 1994 when the list was compiled, 42 units had either closed down or merged with larger units, leaving a total of 288 orthoptic units in the UK. Questionnaire responses were received from 217 departments, a response rate of $75 \%$.

Part 1 requested information about systems currently in place for the assessment of strabismus and amblyopia, and the reasons for choosing them. Most hospitals have more than one system for the assessment of strabismus and amblyopia, which is generally dependent on the route of referral. The most common are 'orthoptic assessment without refraction' (152 (70\%)) and 'orthoptist and ophthalmologist assessment' (149 (69\%)) (Table 1). Each unit had considered a number of factors when choosing a system. One hundred and forty-two units had chosen a system because they thought it 'worked well'. Thirty units felt that the system in place had resulted from a shortage of ophthalmologists. Forty-four units had considered 'value for money' when devising their system (Table 2).

Part 2 enquired about the tests used routinely in the

Table 1 Systems in place for the assessment of children with suspected strabismus or amblyopia. Some departments have more than one system in place, thus the total exceeds the 217 respondents

\begin{tabular}{|c|c|}
\hline & Number \\
\hline Orthoptist assessment without refraction & 152 \\
\hline Orthoptist assessment with autorefraction & 45 \\
\hline $\begin{array}{l}\text { Orthoptist assessment with retinoscopy by } \\
\text { orthoptist }\end{array}$ & 16 \\
\hline Orthoptist and ophthalmologist assessment & 149 \\
\hline $\begin{array}{l}\text { Orthoptist assessment and refraction by optometrist } \\
\text { in same hospital clinic }\end{array}$ & 81 \\
\hline $\begin{array}{l}\text { Orthoptist assessment and refraction by optometrist } \\
\text { in same community clinic }\end{array}$ & 33 \\
\hline $\begin{array}{l}\text { Orthoptist assessment and subsequent referral to } \\
\text { optometrist practice for refraction }\end{array}$ & 43 \\
\hline $\begin{array}{l}\text { Orthoptist assessment and referral to ophthalmic } \\
\text { medical practitioner in community }\end{array}$ & 23 \\
\hline
\end{tabular}


Table 2 Reasons cited for choosing the systems currently in place for the assessment and management of strabismus and amblyopia. Respondents were allowed to choose more than one reason

\begin{tabular}{lc}
\hline & Number \\
\hline Tradition & 62 \\
Continuity of care & 63 \\
Works well & 142 \\
Shortage of ophthalmologists & 30 \\
To improve on previous system & 79 \\
Value for money & 44 \\
No other option & 32 \\
\hline
\end{tabular}

initial assessment of children, eg methods of measuring visual acuity. The initial orthoptic assessment of a suspected case of amblyopia/strabismus was fairly uniform and included cover test, ocular movement, motor fusion and stereopsis.

There was considerable variation across the country in the assessment of visual acuity (Table 3). Twentyone units use logMAR (EDTRS) to assess visual acuity in children $>2.5$ years. A large number of units ( $n=171,79 \%$ ) attempt to measure the visual acuity of children under 1 year old as part of their routine assessment for amblyopia. Most units ( $n=186,84 \%)$ regularly measure the acuity of children in the 1-2.5 year old age group. Kay's pictures are the most common method in use in this age group $(n=182)$, but other methods commonly in use include Cardiff cards $(n=49)$, and the Sheridan Gardiner test $(n=48)$ and 100 s and 1000s $(n=20)$.

Ophthalmologists and/or optometrists are involved in refraction and fundus checks in 182 and 178 units respectively (Table 4 ). Some units do not undertake refraction or fundoscopy ( $\mathrm{n}=32$ and $n=36$, respectively), but these are community orthoptic clinics, which refer children with any problems to a hospital-based clinic for further evaluation.

Table 3 Tests of visual acuity used in the assessment of children and the age at which they are routinely carried out

\begin{tabular}{lcccc}
\hline \multirow{2}{*}{$\begin{array}{l}\text { Test of visual } \\
\text { acuity }\end{array}$} & \multicolumn{4}{c}{ Age test performed } \\
\cline { 2 - 5 } & $<1$ year & $1-2.5$ years & $>2.5$ years & Not done \\
\hline Acuity card & 84 & 1 & 0 & 129 \\
procedure & & & & \\
Cardiff cards & 138 & 49 & 0 & 25 \\
Kays pictures & 1 & 182 & 5 & 4 \\
Keeler & 5 & 4 & 6 & 174 \\
LogMAR & 0 & 2 & 19 & 163 \\
(EDTRS) & & & & \\
Sheridan & 0 & 48 & 125 & 14 \\
Gardiner & & & & \\
Snellen & 0 & 3 & 151 & 27 \\
\hline
\end{tabular}

Table 4 Professionals responsible for carrying out refraction and fundoscopy within a department

\begin{tabular}{lcc}
\hline & Refraction & Fundoscopy \\
\hline Ophthalmologist & 96 & 127 \\
Optometrist & 40 & 10 \\
Either ophthalmologist or & 46 & 39 \\
optometrist & 32 & 36 \\
Not done & & \\
\hline
\end{tabular}

Part 3 enquired about the management of children who had no evidence of strabismus or amblyopia at the first visit. Eight per cent (18) of units would discharge a child who was found to have no strabismus or amblyopia at the first visit, while $77 \%$ (164) review some children and 15\% (31) review all.

In the 174 orthoptic units continuing to follow up some children, criteria for further follow-up included family history $(n=90)$, parental concern $(n=70)$, poor co-operation $(n=50)$ and age of child $(n=45)$ (Table 5). Where age was used as a criterion for further review, 22 units continued until the age of 3.5 years, 21 units until 2.5-3 years, three units until 2 years and 19 units failed to specify a particular age for discharge. Criteria for follow-up in units reviewing all children were: obtaining an accurate visual acuity $(n=12)$, a normal visual acuity $(n=16)$ and a normal orthoptic assessment $(n=13)$.

Part 4 enquired about whether an entirely orthoptist/optometric service had been considered for the management of children suspected of having strabismus or amblyopia. Reasons for not wanting such a system were then asked for. Forty-seven (22\%) units in the UK have an entirely orthoptic/optometric management plan. One hundred and twenty-six units did not feel that this system was appropriate stating that orthoptists were not qualified to refract or conduct fundoscopy ( $n=71,56 \%)$, no optometrist service was

Table 5 Criteria used for the continued follow-up of children following a normal orthoptic assessment. Units are divided into those that continued to follow up all children and those that only reviewed some

Reviewed all Reviewed some

\begin{tabular}{lrr}
\hline Family history & 4 & 90 \\
Accurate visual acuity & 12 & 26 \\
Parental concern & 3 & 70 \\
Poor co-operation & 2 & 50 \\
Age & 7 & 45 \\
Refractive error & 4 & 12 \\
Normal visual acuity & 16 & 26 \\
No evidence of a heterophoria & 0 & 3 \\
Normal orthoptic assessment & 13 & 20 \\
History of strabismus & 0 & 2 \\
\hline
\end{tabular}

Accurate visual acuity

Age

Normal visual acuity

Normal orthoptic assessment

History of strabismu 
available $(n=57,45 \%)$, and resistance from ophthalmologists $(n=49,39 \%)$ (Table 6). No unit volunteered resistance from orthoptists.

Part 5 enquired about the involvement of an ophthalmologist in the management of children with amblyopia or strabismus. Ophthalmologists are involved in the initial assessment of children in 145 units. Thirteen of these units only saw an ophthalmologist again if they failed to respond to treatment $(n=7)$, needed surgery $(n=5)$, or had poor visual acuity $(n=1)$. Thirteen units only involved an ophthalmologist if surgery was required. Thirty units involved an ophthalmologist if the response to orthoptic treatment was poor: defined as a visual acuity of $6 / 9-6 / 18(n=23)$, or $6 / 24$ or worse $(n=7)$ in the amblyopic eye. Twenty-two of the 47 units who had an entirely orthoptist/optometric management plan also had an alternative system in which an ophthalmologist was involved at the initial visit.

In retrospect, we appreciate that certain sections of the questionnaire contained ambiguities that were not identified in the initial piloting of the questionnaire. These sections have been excluded from analysis and are not presented here.

\section{Discussion}

This study highlights diversity in two aspects of the assessment and management of amblyopia and strabismus: first in the systems in place for assessment and management, and second in the techniques used to assess infants and young children suspected of having these conditions.

Children suspected of having amblyopia or strabismus enter the ophthalmic service predominantly by three routes: preschool screening, referral of an asymptomatic child from an at-risk group (eg, expreterm, neuro-developmental delay and a child with a disability), and symptomatic referral. The last named can arise from a number of community or hospital healthcare sources.

Table 6 Reasons for not wanting to adopt an entirely orthoptic/optometric run system

\begin{tabular}{lc}
\hline & Number \\
\hline Insufficient number of qualified orthoptists & 10 \\
Orthoptist not qualified in refraction and fundus & 71 \\
examination & \\
No optometrist service available & 57 \\
Resistance from ophthalmologists & 49 \\
Resistance from optometrists & 10 \\
Parental expectation to be seen by a doctor & 18 \\
Not safe & 19 \\
Other & 0 \\
\hline
\end{tabular}

Once within the ophthalmic system how the child is assessed and subsequently managed also varies. The ophthalmic team contains a number of professions (ophthalmologist, orthoptist, optometrist and nurse) whose roles differ across the country according to local practices, as shown in this survey. Given these differing routes of referral, service structure and the diversity of the population, it is not surprising that many ophthalmic departments have more than one assessment and management scheme. Indeed this is entirely appropriate. For instance, the healthy young strabismus suspect is ideally assessed by an orthoptist working with an optometrist, whereas the child with neurodevelopmental delay requires a full ophthalmic evaluation. Children within at-risk groups are reviewed as clinically indicated and they will not be considered further.

The ensuing discussion focuses on the issue of what the management plan should be for the healthy infant or child who has no evidence of strabismus or amblyopia at an initial assessment. Our survey showed that only $8 \%$ of units felt justified in discharging these children at the first visit, while the majority continued to monitor children, in particular those with a family history, refractive error and parental concern. This review process places considerable demands on the family and ophthalmic resources, so it is now pertinent to consider the role of these risk factors in determining the need for follow up. The links between these three factors and strabismus are well known, however their predictive value is less certain. ${ }^{23}$ The questions arise: How can we determine at risk children from a single evaluation? What tests are required to identify risk factors and at what age are these risk factors most significant?

This survey sought information about the techniques of assessment of the infant and child suspected of having amblyopia and/or strabismus. Here we will focus on the measurement of visual acuity and refractive state. Measurement of visual acuity in young children is the Achilles heel of paediatric ophthalmology, fully reflected in this study by the wide range of tests being utilised. Acuity testing at the age of 2 years results in a high rate of false positives $(86.3 \%)$ compared with that at the age of 3 years $(54.7 \%){ }^{24}$ It is well established that grating tests such as the acuity card procedure underestimate the depth of amblyopia compared to tests of recognition acuity. ${ }^{25,26}$ To measure amblyopia precisely, a crowded optotype test is necessary. Although accurate Snellen acuities are obtained in $80 \%$ of children at the age of 3 years, this increases to $90 \%$ by 3.25 years. ${ }^{18}$ In 1976 Bailey and Lovie developed the logMAR test as an alternative to the Snellen chart in order to surmount its 
All Health Visitor and GP referrals for suspected strabismus over 9 months of age: (excluding neurodevelopmental delay and expreterm children)

\author{
Positive family history / Continued parental concern \\ Positive cover test* \\ Abnormal ocular movements* \\ Visual Acuity of $<6 / 6 \&$ /or 1 line difference at $\geq 2.5$ years** \\ Stereopsis reduced $* * *$ \\ Fusion absent $* * * *$ \\ Any other pathology \\ Refraction (cyclopentolate 1\%)***** \\ Myopia \\ Hyperopia $\geq+2.50 \mathrm{DS}$ \\ Astigmatism $\geq 1.00$ \\ Anisometropia $>0.75$ DS \\ If yes to any of these \\ refer to Children's \\ Eye Clinic. \\ If no to all of these \\ then discharge
* Decision about which cover test and eye movement abnormalities require referral is a clinical judgement.
**Visual Acuity: Single optotype letters are used. If unable to do this then use Kay's. $* * *$ Stereopsis: $<3$ years $<550$ secs (lang). $\geq 3$ years $<100$ secs.
$* * * *$ Fusion: $<3$ years $+/$ - to 20 dioptres; $\geq 3$ years $\geq 20$ dioptre PFR.
$* * * * *$ Refractive values allow for distance alone - nothing allowed for cycloplegia

Figure 1 Fast track clinic protocol used at the Children's Eye Service, St Mary's Hospital, London.

shortcomings, ie irregular progression of letter sizes, variation in the number of letters on each line and unequal legibility of letters used. ${ }^{27-32}$ Accordingly, $\log$ MAR charts are now routinely employed in clinical vision scientific research and increasingly in routine clinical practice. ${ }^{33}$ Detection rates for amblyopia using the logMAR test are twice those of Snellen charts, and reproducibility is superior to Snellen-obtained measures, yet only $25 \%$ of UK units have taken to using them. ${ }^{27,28,29,33,34}$ It is universally recognised that 'objection to occlusion' is of great value in identifying the presence of amblyopia in very young children. However, attempts to precisely quantify the visual deficit in a standard clinical setting, in children under about 2.5 years, is fraught with difficulty and is of debatable value, because testing generates many spurious results. Yet, our survey showed that such measurements are attempted in 171 units for children under 1 year of age and 186 units for children of 1-2.5 years of age. There is a need to rationalise visual acuity testing in young children for the purpose of identifying and quantifying amblyopia. In the meantime, the need for the continued review of children who are otherwise normal, on the basis of visual acuity alone should be questioned.

The association between hypermetropia and the development of strabismus is well documented..$^{35-38}$ However, studies linking refractive error (eg astigmatism, spherical error and anisometropia) with strabismus and amblyopia show that because of refractive changes during childhood, more than one measurement is required to determine a child's risk of developing amblyopia or strabismus. ${ }^{35,37}$ This is due to the process of emmetropisation which is largely complete by the age of 2 years but may continue until 4 years of age. ${ }^{35,36}$ The management of a child, with what is considered to be a borderline error under the age of 4 , is controversial due to uncertainty over the significance of these findings. Relative risks have been assigned to certain refractive errors, however in terms of screening, hypermetropia in the order of 3.5 spherical dioptres or 2 dioptres in one meridian, are both risk factors for amblyopia. ${ }^{35-39}$ Increasing astigmatism, oblique astigmatism and presence of strabismus have the highest relative risk. ${ }^{36,39,40}$ The benefit of early detection and treatment of refractive errors has also been the subject of considerable debate, ${ }^{41-43}$ with evidence both for and against early correction. $^{41,44}$ Thus, the appropriate management of a child with a refractive error depends on the age of the child, the type of refractive error and the presence or absence of strabismus. 
The incidence of strabismus increases to $17.6 \%$ (vs 3 $4 \%$ ) when a positive family history is elicited. ${ }^{35}$ The risk of developing esotropia in patients with a positive family history is increased four-fold in the presence of hypermetropia. ${ }^{36}$ Rosner and Rosner showed that given superficial instruction, parents can detect $66-76 \%$ strabismus, ${ }^{45-47}$ although in the absence of strabismus (as in anisometropia) only $17 \%$ of children with amblyopia were noticed by their parents. ${ }^{48}$ While the predictive value of family history, in the absence of other amblyopia risk factors, is not known, a positive family history of amblyopia is probably a valid reason on its own for reviewing the amblyopia and strabismus suspect. The healthy child without a positive family history, or evidence of refractive error, strabismus or amblyopia on initial assessment is most unlikely to develop amblyopia or strabismus.

This survey has highlighted several professional issues. While it is recognised that local issues influence professional roles, it is unlikely that they account for all the variations reported herein. Forty-seven units have a completely orthoptic/optometric run system, but many units were reluctant to adopt such a system. Reasons given included othoptists not being trained in refraction, lack of optometry services and resistance from ophthalmologists. Most units still prefer to have a consultant ophthalmologist involved at the start of treatment-usually to confirm the absence of ocular pathology. Ophthalmologists tend to be involved at the commencement of treatment, when there is a poor therapeutic response, and if surgery is to be considered. Ophthalmologists are relatively infrequently involved in children with suspected strabismus and the management of amblyopia and accommodative esotropia. ${ }^{49}$

Studies have shown that orthoptists are the most effective screeners of strabismus and amblyopia $20,21,50,51$ and given suitable training they are also able to refract. ${ }^{52}$ While the debate on preschool vision screening continues, primary screening backed up by secondary orthoptic/optometric assessment has been shown to substantially decrease the number of inappropriate referrals to hospital clinics. ${ }^{33,51,53-58}$ Where this occurred, only $14 \%$ were referred to the hospital clinic, of whom $76 \%$ were referred back to the community for subsequent full or partial management. ${ }^{54}$ Such schemes have also demonstrated that children are referred earlier for treatment (average age decreased from 6.6 years to 5 years) and that the relationship between social deprivation and the age of presentation of asymptomatic amblyopia is abolished. ${ }^{12}$

\section{Conclusion}

There is considerable variation across the country in the way that we assess and review children suspected of harbouring strabismus and/or amblyopia. Therefore many children continue to be followed up despite having no ophthalmic abnormality. This places a considerable burden on the NHS and is of no benefit to the child. Further work is necessary to determine the value of individual tests at different ages, and only then can clear management criteria be drawn up. Hypermetropia, especially if unilateral, and a positive family history are risk factors for amblyopia and strabismus, and in their absence, the review of a child is probably not indicated. While the diagnostic value of simple qualitative tests is not in doubt, the detailed measurement of visual acuity for the amblyopia and strabismus suspect under 2.5 years of age, in a routine clinical setting, is doubtful.

A number of fundamental questions still remain about the methodology of screening: efficacy, validity and cost effectiveness. While it is recognised that further research is required, several centres have already introduced models of practice that are community based and utilise orthoptic optometric teams. ${ }^{54}$ Our unit, which serves an area without community screening, uses the following protocol to diagnose strabismus and amblyopia: identify at risk children, and discharge as soon as possible those who are not at risk-so minimising unnecessary follow up visits (as shown in Figure 1).

There are a bewildering number of systems in place for the assessment and management of amblyopia and strabismus and their simplification would facilitate the development of cohesive children's ophthalmic services. It is our opinion that, while the full ophthalmic team should be involved in developing integrated care pathways, much of the assessment and subsequent management can be undertaken by orthoptists working with optometrists.

\section{References}

1 Graham PA. Epidemiology of strabismus. Br J Ophthalmol 1974; 58: 224-231.

2 Stidwell D. Epidemiology of strabismus. Ophthal Physiol Opt 1997; 17: 536-539.

3 Frandsen AD. Occurrence of squint: a clinical statistical study on the prevalence of squint and associated signs in different groups and ages of the Danish population. Acta Ophthalmol (Copenh) 1960; 62: 1-157.

4 Flom MC, Bedell HE. Identifying amblyopia using associated conditions, acuity and non-acuity features. Am J Optom Physiol Opt 1985; 62: 153-160.

5 Woodruff ME. Vision and refractive status among grade 1 children of the province of New Brunswick. Am J Optom Physiol Opt 1986; 63: 545-552. 
6 Chew EE, Remaley NA, Tamboli A, Zhao J, Podgor MJ, Klebanov M. Risk factors for esotropia and exotropia. Arch Ophthalmol 1994; 112: 1349-1353.

7 Von Noorden GK. Binocular Vision and Ocular Motility, 4th edn. CV Mosby: St Louis, 1990, p 216.

8 Von Noorden GK, Crawford MLJ. The sensitive period. Trans Ophthalmol Soc UK 1979; 99: 442-446.

9 Edwards RS, Abbott AG, Whitelaw AL. The outcome of pre-school visual screening. Br Orthopt J 1993; 50: 2-6.

10 Vaegan, Taylor D. Critical period for deprivation amblyopia. Trans Ophthalmol Soc UK 1979; 99: 432-439.

11 Flynn JT. Current trends in amblyopia therapy. Ophthalmology 1978; 85: 428-450.

12 Shaw DE, Fielder AR, Minshull C, Rosenthal AR. Amblyopia-factors influencing age of presentation Lancet 1988; ii: 207-209.

13 Smith L, Thompson JR, Woodruff G. Children's vision screening: impact on inequalities in central England. J Epidemiol Community Health 1995; 49: 606-609.

14 Committee on Child Health Services. Fit for the Future (Court Report) HMSO: London, 1976

15 Stewart-Brown SL, Haslum MN, Howlett B. Preschool vision screening: a service in need of rationalisation. Arch Dis Child 1988; 63: 356-359.

16 Snowdon S, Stewart-Brown S. Preschool Vision Screening: Results of a Systematic Review. CRD Report 9, The University of York, 1997.

17 Simons K. Preschool vision screening: rationale, methodology and outcome. Surv Ophthalmol 1996; 41: 325 .

18 Hall DMB. Health for all Children, 3rd edn. Oxford University Press: Oxford, 1996, Ch 11.

19 Blair M. The needs for and the role of a coordinator in child health surveillance/promotion. Arch Dis Child 2001; 84: $1-5$.

20 Edwards RS, Abbott AG, Whitelaw AJ. The outcome of preschool visual screening. Br Orthop J 1993; 50: 2-6.

21 Bray LC, Clarke MP, Jarvis SN, Francis PM, Colver A Preschool vision screening: a prospective comparative evaluation. Eye 1996; 10: 714-718

22 Jarvis SN, Tamhne RC, Thompson L, Francis PM, Anderson J, Colver AF. Preschool vision screening. Arch Dis Childhood 1990; 65: 288-294.

23 Lennerstrand G. In: Lennerstrand G, von Noorden GK, Campos EC (eds). Strabismus and Amblyopia. Wenner Gren International Symposium Series. Macmillan: London, 1987, pp 5-21.

24 McNamara RM, Duckworth S. The effect of removing vision testing from child surveillance programmes. $\mathrm{Br}$ Orthopt J 1998; 55: 26-31.

25 Fielder AR, Dobson V, Moseley MJ Mayer DL. Preferential looking-clinical lessons. Ophthal Paed Genet 1992; 13: 101-110.

26 Levi DM, Klein S. Differences in vernier discrimination for grating between strabismus and anisometropic amblyopes. Invest Ophthalmol Vis Sci 1982; 23: 398-407.

27 Stewart C. Comparison of Snellen and log-based acuity scores for school aged children. Br Orthopt J 2000; 57: 32 38.

28 Lovie-Kitchen JE. Validity and reliability of visual acuity. Ophthal Physiol Opt 1988; 8: 363-370.

29 McGraw PV. Studies of human macular function: developmental anomalies. PhD thesis, Glasgow Caledonian University, 1995.
30 Bailey IL, Lovie JE. New design principles for visual acuity letter charts. Am J Optom Physiol Opt 1976; 53: 740745

31 Bailey IL, Bullimore MA, Raasch TW, Taylor HR. Clinical grading and the effects of scaling. Invest Ophthalmol Vis Sci 1991; 32: 422-432.

32 Hyvarinen L, Nasanen R, Laurinen P. New visual acuity test for preschool children. Acta Ophthalmol (Copnh) 1980; 58: 507-511.

33 Hartmann EE, Dobson V, Hainline L et al. Preschool vision screening: summary of a task force report. Ophthalmology 2001; 108: 479-486.

34 McGraw PV, Winn B, Gray LS, Elliott DB. Improving the reliability of visual acuity measures in young children. Ophthal Physiol Opt 2000; 20: 173-184.

35 Aurell E, Norrsell K. A longitudinal study of children with a family history of strabismus: risk factors determining the incidence of strabismus. $\mathrm{Br}$ J Ophthalmol 1990; 74: 589-594.

36 Sjostrand J, Abrahamsson M. Risk factors in amblyopia. Eye 1990; 4: 787-793.

37 Ingram RM, Walker C, Wilson JM, Arnold PE, Dally S. Prediction of amblyopia and squint by means of refraction at age 1 year. $\mathrm{Br}$ J Ophthalmol 1986; 70: 12-15.

38 Fabian G. Ophthalmological serial examinations of 1200 children in their 2nd year of life. Acta Ophthalmol (Copenh) 1966; 49: 473-479.

39 Abrahamsson M, Fabian G, Anderson AK, Sjostrand J. A longitudinal study of a population based sample of astigmatic children. II: The changeability of anisometropia. Acta Ophthalmol (Copenh) 1990; 68: 435-440.

40 Ingram RM, Barr A. Changes in refraction between 1 and 3.5 years. Br J Ophthalmol 1979; 63: 339-342.

41 Ingram RM, Arnold PE, Dally S, Lucas J. Emmetropisation, squint and reduced visual acuity after treatment. Br J Ophthalmol 1991; 75: 414-416.

42 Ingram RM, Arnold PE, Dally, Lucas J. Results of a randomised trial of treating abnormal hypermetropia from the age of 6 months. Br J Ophthalmol 1990; 74: 158159.

43 Ingram RM, Gill LE, Lambert TW. Effect of spectacles on changes of spherical hypermetropia in infants who did, and did not, have strabismus. $\mathrm{Br}$ J Ophthalmol 2000; 84: 324-326.

44 Atkinson J, Braddick O, Bobier B, Anker S, Ehrlich D, King $\mathrm{J}$ et al. Two infant visions screening programmes: prediction and prevention of strabismus and amblyopia from photorefractive screening. Eye 1996; 10: 189-198.

45 Rosner J, Rosner J. Parents as screeners for strabismus in their children. I Visual Impairment and Blindness 1988; 83: 193-194.

46 Hall DM, Hall SM. Early detection of visual defects in infancy. Br Med J 1988; 296: 823-824.

47 Hall SM, Pugh AG, Hall DM. Vision screening in the under 5's. Br Med J 1982; 285: 1096-1098.

48 Wang YD, Thompson JR, Goulstine DB, Rosenthal AR. A survey of the initial referral of children to an ophthalmology department. Br J Ophthalmol 1991; 74: 650653

49 McCarry B. Orthoptists' current shared care role in ophthalmology. Br Orthopt J 1999; 56: 11-18.

50 Townsend K. 'A model of care': looking at the referral, diagnostic and clinical outcomes of an integrated visual 
screening programme, 1995/6 to 1998. Br Orthopt J 1999; 56: 31-36.

51 Bolger PG, Stewart-Brown SL, Newcombe E, Starbuck A. Vision screening in preschool children: comparison of orthoptists and clinical medical officers as primary screeners. Br Med J 1991; 303: 1291-1294.

52 Arnold PE, Billingham BA, McGarrigle M. Can orthoptists refract? Br Orthopt J 1991; 48: 46-47.

53 Simons K, Preslan M. Natural history of amblyopia untreated owing to lack of compliance. $\mathrm{Br} J$ Ophthalmol 1999; 83: 582-587.

54 Karas M, Donaldson L, Charles A et al. Paediatric community vision screening-a new model. Ophthal Physiol Opt 1999; 19: 295-299.
55 Rahi JS, Williams C, Benford H, Elliman D. Screening and surveillance for ophthalmic disorders and visual deficits in children in the United Kingdom. Br J Ophthalmol 2001; 85: 257-259.

56 Griffiths PG, Clarke M. Visions screening in preschool children. Br Med J 1992; 304: 253.

57 Madlom MM. Vision screening in preschool children. $\mathrm{Br}$ Med J 1992; 304: 253.

58 Tomilla V, Tarkkaren A. Incidence of loss of vision in the healthy eye in amblyopia. Br J Ophthalmol 1981; 65: 575577. 